\title{
A STUDY OF FATIGUE COMPLAINTS AMONG WORKERS EXPOSED TO HEAT STRESS IN AN ELECTRONIC COMPANY IN HANOI, VIETNAM
}

\author{
SHINYA MATSUDA \\ Received November 28, 1994/Accepted January 30, 1995
}

\begin{abstract}
The relation between exposure to heat stress in the workplace and the degree of fatigue complaints was investigated by a questionnaire (composed of 30 items) among 39 assembly line workers in an electronic factory in Hanoi, Vietnam. There is a considerable difference in the change of fatigue complaints before and after work between workers exposed to heat and those not exposed. Among the workers not exposed to heat stress, the rate of fatigue complaints increased in 8 items, all of which did not show any statistically significant change during the work. In the case of workers under heat stress, the rate increased in 25 items, of which nine showed statistically significant increase after working hours. Especially, the changes were more apparent among the items corresponding to 'drowsiness and dullness'. A special consideration must be paid to heat stress in tropical countries such as Vietnam, in order to prevent occupational impairment.
\end{abstract}

\section{INTRODUCTION}

After the introduction of the new open market policy in 1986, Vietnam has begun to realize a rapid economic growth. Especially, the permission for foreign companies to invest in the country has made it possible to organize a number of joint ventures between Vietnam and other countries. It is expected that the living conditions of the Vietnamese will be improved gradually by the stabilization of the national economy. However, this rapid economic development may cause an intensification of labor, especially in the newly developed factories, most of which are labor intensive sectors, such as textile industries and food processing factories. Various "newly adopted" work conditions (i.e., shift work, assembly line, etc) have been adopted in these workplaces, where the standards of labor safety and hygiene are not always respected ${ }^{11}$. As a result, various health problems at the workplaces have emerged in addition to the traditional occupational health problems (i.e., silicosis, saturism, etc). To evercome these problems, much attention to occupational safety from the ergonomic point of view must be paid in the developing countries like Vietnam. It is well known that most occupational accidents occur due to the lack of attention of workers and that a mentally exhausting situation is very apt to cause severe occupational accidents. In tropical coun- tries like Vietnam, the exhausting working conditions are very energy consuming both physically and mentally. Therefore, a special consideration should be given to the working conditions in a tropical environment. In this report, I present the results of studies focusing on the relation between the heat stress and complaints of fatigue of assembly line workers in an electronic company in Hanoi, Vietnam.

\section{STUDY AND METHODS}

An electronic company in Hanoi, Vietnam was selected for the study. This factory, which was established as a joint venture between Korea and Vietnam, produces 10 thousand television sets per month on an assembly line. The average working time is from 8:00 am to $5: 00 \mathrm{pm}$ (there is a two-hour rest at lunch time). The two most important origins of heat in the factory are the workplaces where the assembled monitor is checked, and where the soldering machine is located.

Thirty-nine assembly line workers were investigated regarding their working conditions as well as fatigue complaints before and after work, by using two questionnaires. All questionnaires were completed by the workers themselves. The first questionnaire was prepared in order to obtain background information such as; age, sex, educational level, living conditions (i.e., size

Department of Preventive Medicine and Community Health, University of Occupational and Environmental Health, Japan 
of house, number of family members), monthly income, distance between residence and factory, hazardous conditions at the workplace (i.e., heat, noise, chemicals, radiation, etc). The second questionnaire was the fatigue questionnaire developed by the Japan Association of Industrial Health, which is composed of 30 questions under three categories; the first 10 items are related to "Drowsiness and dullness", the second 10 items to "Difficulty in concentration", and the last 10 items to "Projection of physical disintegration"). The questionnaire was administrated before and after work in order to monitor the changes in subjective fatigue symptoms during the working hours.

The basic statistics of the workers are as follows: Sex distribution: 28 males and 11 females,

The average age of workers: $26.8(\mathrm{SD}=8.0, \mathrm{Min}=$ $15, \operatorname{Max}=48$ ),

Number of workers exposed to heat: 28

At first I conducted an analysis stratified by sex, but as there was no difference between the two, I will show the result of combined sex analysis in order to

Table 1 Changes in the rate of those who had corresponding fatigue complaints before and after work in an electric company at Hanoi, Vietnam (stratified by the existence of heat stress, $\mathrm{n}=39$ )

\begin{tabular}{|c|c|c|c|c|c|c|c|c|}
\hline \multirow{3}{*}{ Complaints } & \multicolumn{3}{|c|}{ Heat $(-)(n=11)$} & \multicolumn{3}{|c|}{ Heat $(+)(n=28)$} & \multirow{2}{*}{\multicolumn{2}{|c|}{$\begin{array}{c}\text { Significance of difference } \\
\text { due to heat** }\end{array}$}} \\
\hline & \multirow{2}{*}{$\begin{array}{c}\text { Before work } \\
(\%)\end{array}$} & \multirow{2}{*}{$\begin{array}{l}\text { After work } \\
(\%)\end{array}$} & \multirow{2}{*}{$\begin{array}{l}\text { Significance } \\
\text { of change* }\end{array}$} & \multirow{2}{*}{$\begin{array}{c}\text { Before work } \\
(\%)\end{array}$} & \multirow{2}{*}{$\begin{array}{l}\text { After work } \\
(\%)\end{array}$} & \multirow{2}{*}{$\begin{array}{l}\text { Significance } \\
\text { of change* }\end{array}$} & & \\
\hline & & & & & & & Before work & After work \\
\hline \multicolumn{9}{|l|}{ I. Drowsiness and dullness } \\
\hline 1 feel heavy in the head & 9.1 & 18.2 & $\mathrm{p}=0.317$ & 25.0 & 67.9 & $\mathrm{p}=0.005$ & $\mathrm{p}=0.262$ & $\mathrm{p}=0.005$ \\
\hline 2 get tired of the whole body & 36.4 & 63.6 & $\mathrm{p}=0.109$ & 32.1 & 82.1 & $\mathrm{p}=0.004$ & $\mathrm{p}=0.801$ & $\mathrm{p}=0.205$ \\
\hline 3 legs feel heavy & 0.0 & 9.1 & $\mathrm{p}=0.317$ & 0.0 & 17.9 & $\mathrm{p}=0.043$ & N.C. & $\mathrm{p}=0.447$ \\
\hline 4 give a yawn & 18.2 & 18.2 & $\mathrm{p}=1.000$ & 21.4 & 28.6 & $\mathrm{p}=0.361$ & $\mathrm{p}=0.821$ & $\mathrm{p}=0.409$ \\
\hline 5 feel the brain muddled & 18.2 & 18.2 & $\mathrm{p}=1.000$ & 0.0 & 21.4 & $\mathrm{p}=0.028$ & $\mathrm{p}=0.074$ & $\mathrm{p}=0.599$ \\
\hline 6 become drowsy & 18.2 & 45.5 & $\mathrm{p}=0.109$ & 35.4 & 53.6 & $\mathrm{p}=0.139$ & $\mathrm{p}=0.286$ & $\mathrm{p}=0.648$ \\
\hline 7 feel strained in the eyes & 36.4 & 36.4 & $\mathrm{p}=1.000$ & 32.1 & 64.3 & $\mathrm{p}=0.008$ & $\mathrm{p}=0.801$ & $\mathrm{p}=0.111$ \\
\hline 8 become rigid or clumsy in motion & 0.0 & 9.1 & $\mathrm{p}=0.317$ & 0.0 & 14.3 & $\mathrm{p}=0.068$ & N.C. & $\mathrm{p}=0.562$ \\
\hline 9 feel unsteady in standing & 0.0 & 0.0 & $\mathrm{p}=1.000$ & 0.0 & 0.0 & $\mathrm{p}=1.000$ & N.C. & N.C. \\
\hline 10 want to lie down & 9.1 & 0.0 & $\mathrm{p}=0.317$ & 3.6 & 14.3 & $\mathrm{p}=0.109$ & $\mathrm{p}=0.490$ & $\mathrm{p}=0.249$ \\
\hline Average number of items marked in I & 1.5 & 2.2 & $\mathrm{p}=0.054^{* * *}$ & 1.5 & 3.6 & $\mathrm{p}=0.000 * * *$ & $\mathrm{p}=0.949^{* * *}$ & $\mathrm{p}=0.066^{* * *}$ \\
\hline \multicolumn{9}{|l|}{ II. Difficulty in concentration } \\
\hline 11 feel difficult in thinking & 0.0 & 0.0 & $\mathrm{p}=1.000$ & 7.1 & 17.9 & $\mathrm{p}=0.109$ & $\mathrm{p}=0.510$ & $\mathrm{p}=0.171$ \\
\hline 12 become weary of talking & 27.3 & 27.3 & $\mathrm{p}=1.000$ & 10.7 & 28.6 & $\mathrm{p}=0.091$ & $\mathrm{p}=0.197$ & $\mathrm{p}=0.632$ \\
\hline 13 feel irritable & 9.1 & 9.1 & $\mathrm{p}=1.000$ & 10.7 & 17.9 & $\mathrm{p}=0.180$ & $\mathrm{p}=0.687$ & $\mathrm{p}=0.447$ \\
\hline 14 unable to concentrate attention & 0.0 & 0.0 & $\mathrm{p}=1.000$ & 0.0 & 0.0 & $\mathrm{p}=1.000$ & N.C. & N.C. \\
\hline 15 become apt to forget things & 18.2 & 9.1 & $\mathrm{p}=0.317$ & 7.1 & 28.6 & $\mathrm{p}=0.028$ & $\mathrm{p}=0.312$ & $\mathrm{p}=0.194$ \\
\hline 16 unable to have interested in things & 9.1 & 9.1 & $\mathrm{p}=1.000$ & 3.6 & 7.1 & $\mathrm{p}=0.317$ & $\mathrm{p}=0.482$ & $\mathrm{p}=0.642$ \\
\hline 17 feel uneasy about things & 0.0 & 0.0 & $\mathrm{p}=1.000$ & 3.6 & 7.1 & $\mathrm{p}=0.317$ & $\mathrm{p}=0.718$ & $\mathrm{p}=0.510$ \\
\hline 18 apt to make mistakes & 9.1 & 0.0 & $\mathrm{p}=0.317$ & 25.0 & 28.6 & $\mathrm{p}=0.317$ & $\mathrm{p}=0.262$ & $\mathrm{p}=0.051$ \\
\hline 19 unable to straighten up in the posture & 27.3 & 27.3 & $\mathrm{p}=1.000$ & 10.7 & 28.6 & $\mathrm{p}=0.043$ & $\mathrm{p}=0.208$ & $\mathrm{p}=0.632$ \\
\hline 20 no energy & 0.0 & 9.1 & $p=0.317$ & 0.0 & 0.0 & $\mathrm{p}=1.000$ & N.C. & $\mathrm{p}=0.282$ \\
\hline Average number of items marked in II & 1.0 & 0.9 & $\mathrm{p}=0.676^{* * *}$ & 0.8 & 1.6 & $\mathrm{p}=0.001^{* * *}$ & $\mathrm{p}=0.696^{* * *}$ & $\mathrm{p}=0.202^{* *}$ \\
\hline \multicolumn{9}{|l|}{ III. Projection of physical disintegration } \\
\hline 21 have a headache & 27.3 & 36.4 & $\mathrm{p}=0.317$ & 25.0 & 53.6 & $\mathrm{p}=0.025$ & $\mathrm{p}=0.884$ & $\mathrm{p}=0.333$ \\
\hline 22 feel stiff in the shoulders & 9.1 & 9.1 & $\mathrm{p}=1.000$ & 21.4 & 39.3 & $\mathrm{p}=0.091$ & $\mathrm{p}=0.346$ & $\mathrm{p}=0.068$ \\
\hline 23 suffer low back pain & 0.0 & 9.1 & $\mathrm{p}=0.317$ & 25.0 & 46.4 & $\mathrm{p}=0.059$ & $\mathrm{p}=0.077$ & $\mathrm{p}=0.030$ \\
\hline 24 feel oppressed in breathing & 0.0 & 0.0 & $\mathrm{p}=1.000$ & 3.6 & 17.9 & $\mathrm{p}=0.068$ & $p=0.718$ & $\mathrm{p}=0.171$ \\
\hline 25 feel thirsty & 27.3 & 27.3 & $\mathrm{p}=1.000$ & 17.9 & 39.3 & $\mathrm{p}=0.059$ & $\mathrm{p}=0.400$ & $\mathrm{p}=0.356$ \\
\hline 26 have a husky voice & 0.0 & 0.0 & $\mathrm{p}=1.000$ & 3.6 & 3.6 & $\mathrm{p}=1.000$ & $\mathrm{p}=0.718$ & $\mathrm{p}=0.718$ \\
\hline 27 have a dizziness & 9.1 & 0.0 & $\mathrm{p}=0.317$ & 7.1 & 32.1 & $\mathrm{p}=0.018$ & $\mathrm{p}=0.642$ & $\mathrm{p}=0.033$ \\
\hline 28 have a spasm on the eyelids & 0.0 & 0.0 & $\mathrm{p}=1.000$ & 0.0 & 3.6 & $\mathrm{p}=0.317$ & N.C. & $\mathrm{p}=0.718$ \\
\hline 29 have a tremor in the limbs & 0.0 & 0.0 & $\mathrm{p}=1.000$ & 3.6 & 10.7 & $\mathrm{p}=0.180$ & $\mathrm{p}=0.718$ & $\mathrm{p}=0.358$ \\
\hline 30 feel unwell & 0.0 & 0.0 & $\mathrm{p}=1.000$ & 0.0 & 0.0 & $\mathrm{p}=1.000$ & N.C. & N.C. \\
\hline Average number of items marked in III & 0.7 & 0.8 & $\mathrm{p}=0.341^{* * *}$ & 1.1 & 2.5 & $\mathrm{p}=0.001^{* * *}$ & $\mathrm{p}=0.515^{* * *}$ & $\mathrm{p}=0.019^{* * *}$ \\
\hline Average number of items marked in Total & 3.2 & 3.9 & $\mathrm{p}=0.195^{* * *}$ & 3.4 & 7.8 & $\mathrm{p}=0.000$ & $\mathrm{p}=0.915^{* * *}$ & $\mathrm{p}=0.032^{* * *}$ \\
\hline
\end{tabular}

${ }^{*}$ : Wilcoxon test (Before and after), ${ }^{* *}$ : Chi square test or Fisher's exact test (Heat + vs. Heat - ), N.C.: Not calculated, ${ }^{* * *}$ : t-test 
increase the statistical stability of the analysis. The changes in fatigue complaints were analyzed before and after work stratified by the existence of heat stress (Wilcoxon test). The differences in the positive rate of fatigue complaints were compared between workers under heat stress and those not exposed (Chi square test, Fisher's exact test and t-test). The SPSSX statistical package in the computer system of UOEH was employed in this investigation.

\section{RESULTS}

Table 1 presents the results concerning changes in subjective fatigue complaints before and after work, stratified by the existence of heat stress in the workplace. There is a considerable difference in the changes of fatigue complaints between two conditions. Among the workers with no heat stress, the rate of workers who had corresponding fatigue complaints increased in only 8 items, all of which did not show any statistically significant change between before and after work. In the case of workers exposed to heat, the rate increased in 25 items, of which nine showed a statistically significant increase after work. Especially, the changes were more apparent among the items of 'Drowsiness and dullness' (i.e., feel in the head, get tired of the whole body, legs feel heavy, feel the brain muddled, feel strained in the eyes). When the average number of marked items before and after work in each three major categories as well as in total was compared, a statistically significant increase was observed among the workers under heat stress in all categories (I: $p=0.000$, II: $p=0.001$, III: $p=0.001$, Total: $p=0.000$; $t$-test), but not among the workers without the stress. When the number of marked items in each category and in total were compared between the two heat exposure conditions before and after work, respectively, the numbers of the two conditions before work were almost the same, but the numbers of marked items were larger among the workers exposed to heat with statistical significance after work (I: $p=0.066$, II: $p=0.202$, III: $p=0.019$, Total: $\mathrm{p}=0.032 ; \mathrm{t}=$ test $)$.

\section{DISCUSSION}

According to the present results, the existence of heat stress at the workplace is significantly associated with the increase of fatigue complaints among the assembly line workers investigated in my study. In Vietnam, special attention should be paid to the existence of heat stress in factories in order to prevent occupational accidents caused by exhaustive conditions of a worker due to heat stress, because heat imbalance may occur even though there is only a slight increase in temperature in a tropical country like Vietnam. The relationship between heat loss/gain variables and internal heat production is described by a simple heat balance equation ${ }^{3)}$ :

$$
\mathrm{S}=(\mathrm{M}-\mathrm{W}) \pm \mathrm{C} \pm \mathrm{R}-\mathrm{E},
$$

where $\mathrm{S}=$ net amount of heat gained or lost by the body,

$\mathrm{M}=$ heat production by metabolism,

$\mathrm{W}=$ external work performed,

$\mathrm{C}=$ heat transfer by convection,

$\mathrm{R}=$ heat transfer by radiation, and

$\mathrm{E}=$ body heat loss by evaporation.

In a tropical country, because the environmental temperature is frequently higher than the surface body temperature, radiation and convection can increase the body temperature. Furthermore, in an extremely warm -moist environment, as found in textile factories located in tropical countries, a more troublesome situation usually arises, where the heat loss by evaporation is completely disturbed. For example, a heat collapse and a heat stroke may easily occur in such a situation. Luong reported that workers in textile factories in Vietnam are usually exposed to temperatures of about $39-40{ }^{\circ} \mathrm{C}$ with $80 \%$ humidity in average ${ }^{4}$. In the present case, workers under heat stress are working in an environment 1 or $2^{\circ} \mathrm{C}$ higher $\left(33-34{ }^{\circ} \mathrm{C}\right)$ than the outdoor temperature, with $80 \%$ humidity (same as the outdoor humidity). Therefore, although we could not detect any severe cases of heat-related illnesses, mild forms of impairment (i.e., irritability, lassitude, decrease in morale, and inability to concentrate) due to the prolonged exposure to the moderately hot climate were observed. This situation can be dangerous in workplaces, especially in a place where enough attention to the occupational safety is not always paid, as is often observed in developing countries like Vietnam. Systematic studies on the effects of exposure to uncomfortably warm environments have clarified that the number of accidents, sickness and labor turnover increases because of their chronic effects on the central nervous system. Inefficiency due to the increase of minor accidents, errors, and slower work rate is also another important problem for developing countries who intend to realize a rapid economic development. In the current situation, both the Vietnamese workers and their employers do not seem to pay any special attention to occupational safety and hygiene such as heat, noise, and other harmful substances (i.e., heavy metals, organic solvents and 
toxic gas), although there is a special regulation legislated by the government for this purpose ${ }^{5)}$. It is natural that a rapid economic development is being given priority in order to stabilize the society in the current situation of Vietnam. In such a situation, it is very difficult to give adequate consideration to the working conditions. According to the results of another questionnaire ${ }^{6)}$, most of the workers, even though they are exposed to some occupational hazards have answered that they are satisfied with the present working conditions, because a stable monthly income is assured, even if there is a possibility of some occupational health impairments in the future. Forty percent of the workers have replied that they will endure some occupational risks to their health in order to earn money to live ${ }^{6)}$. As experienced in Japan, the ignorance of occupational safety and hygiene will have drastic results in the long run. Therefore, special attention must be paid to occupational safety and hygiene from the early stage of industrial development.

A number of studies have been conducted in developed countries, in order to determine the TLV (Threshold Limit Values) of various occupational risks, including temperature at the workplace. For example, the desirable temperatures in the workplace are set as follows; $30.6{ }^{\circ} \mathrm{C}$ (Wet Bulb Globe Thermometer: WBGT) for light work $(235-405 \mathrm{~J} / \mathrm{s}), 28.0{ }^{\circ} \mathrm{C}$ (WBGT) for moderate work (up to $235 \mathrm{~J} / \mathrm{s}$ ) ${ }^{7}$. However, it is not appropriate to apply these standards to developing countries in the tropics, because they have been developed in western countries, most of which are in the temperate zone. There is a difference in heat tolerance and comfortable temperature zone for inhabitants of the tropics and those of other regions. Therefore, different standards must be established in considering the physical and social characteristics of the Vietnamese. However, it is not easy for the Vietnamese researchers to accomplish this task because of the shortage of money, materials and manpower. It is expected that interna- tional collaborative programs in the field of occupational safety and hygiene will be organized in the near future. Finally, in addition to the epidemiological research like the present one, physiological studies must be conducted to establish standards for improving the working condition in Vietnam.

\section{ACKNOWLEDGEMENTS}

This study was conducted with a financial assistance from the Nissan Science Foundation. The author wishes to express his deep gratitude to Mr. N.A. Luong (Director of the National Institute of Labour Protection, Vietnam) for his warm-hearted assistance for the present study in Vietnam. The author is also grateful to Prof. Kahyo (Department of Preventive Medicine and Community Health, U.O.E.H.) for his helpful criticism.

\section{REFERENCE}

1) Thung, D.H., and Trinh, L.V. (1993): Assessment on pollution of working environment in Vietnam and general solution, NILP, Hanoi.

2 ) Industrial Fatigue Research Committee of Japan Association of Industrial Health. (1969): Fatigue Scale of Industrial Fatigue Research Committee of Japan Association of Industrial Health, In: Kyoto Symposium on Methodology of Fatigue Assessment.

3 ) $\mathrm{Hu} \mathrm{H}$. (1988): Other physical hazards and their effects. In: Occupational Health, recognizing and preventing work-related disease, second ed. (ed. Levy, B.S.), 263 -279, Little, Brown and Company, Boston/Toronto.

4 ) Luong, N.A. (1986): Some justifications and data for basis of suggestion to second phase of the project VIE/ 86/018. NILP, Hanoi.

5 ) Matsuda, S. (1995): Ordinance on Labour Protection of Vietnam. The Journal of Science of Labour, 71, 22-30.

6 ) Matsuda, S. unpublished data.

7 ) Bell, C.R. (1989): Heat and hot work. In: Encyclopedia of Occupational Health and safety, Vol. 1, Third ed. (ed: Parmeggiani, L.), 1018-1020, ILO, Geneva. 